\title{
Evaluation of the mechanism of cordyceps polysaccharide action on rat acute liver failure
}

\author{
Lina $G u^{1}$, Ting $Y u^{2}$, Jingyao $L_{i}{ }^{3}$, Ying $L u^{1}$
}

\begin{abstract}
${ }^{1}$ Intensive Care Unit, the First Hospital of Jilin University, Changchun, China 2Department of Nutrition, the Second Hospital of Jilin University, Changchun, China ${ }^{3}$ Department of Neurology, the First Hospital of Jilin University, Changchun, China
\end{abstract}

Submitted: 30 June 2017

Accepted: 19 December 2017

Arch Med Sci 2020; 16 (5): 1218-1225

DOI: https://doi.org/10.5114/aoms.2020.94236

Copyright $\odot 2020$ Termedia \& Banach

\section{Abstract}

Introduction: This study aimed to investigate the mechanism of action of cordyceps polysaccharide on rat acute liver failure (ALF).

Material and methods: Sixty rats were randomly divided into five groups: a normal group, a model group without cordyceps polysaccharide and groups with cordyceps polysaccharide in three different doses $(5,10$ and $20 \mathrm{mg} / \mathrm{ml})$. Serum alanine aminotransferase (ALT), aspartate transaminase (AST), alkaline phosphatase (ALP), and total bilirubin (TBIL) contents were measured for assessing liver function. Hematoxylin and eosin (HE) staining was used for observing liver pathology. Apoptosis was detected through the method of terminal-deoxynucleotidyl transferase mediated nick end labeling (TUNEL) staining. Protein expression levels of caspase-1, interleukin-18 (IL-18), IL-10, vascular endothelial growth factor (VEGF), and stromal cell-derived factor- $1 \alpha$ (SDF-1 $\alpha$ ) in liver tissue were detected by Western blot. Proliferating cell nuclear antigen (PCNA) and signal regulatory protein- $\alpha 1$ (SIRP $\alpha 1)$ contents were measured by PCR.

Results: The rat ALF model was established with D-galactosamine induced by lipopolysaccharide (LPS). After modelling, tissue HE staining showed typical manifestation of acute liver injury that emerged in the rat ALF model. The liver failure group showed higher levels of serum ALT and AST, as well as hepatocyte apoptosis, than the groups treated with cordyceps polysaccharide. Cordyceps polysaccharide can effectively suppress the protein expression of caspase-1, IL-18, and IL-10, while simultaneously increasing the protein expression of VEGF and SDF-1 $\alpha$, as well as the mRNA expression of PCNA and SIRP $\alpha 1$.

Conclusions: Cordyceps polysaccharide can alleviate the immune response and inflammatory injury in ALF by regulating the balance of pro-inflammatory and anti-inflammatory factors and reducing the apoptosis.

Key words: cordyceps polysaccharide, rat acute liver failure, caspase-1, interleukin-18, hepatocyte proliferation.

\section{Introduction}

Acute liver injury (ALF) is a liver injury syndrome with high lethality and mainly caused by a variety of liver diseases [1]. Liver cell transplantation is a new therapeutic tool to treat a variety of liver diseases; however, there are still several shortcomings limiting its application, low cell engraftment, and a short-lasting effect, due to which the patients tend to have a poor prognosis [2-5].

\author{
Corresponding author: \\ Ying Lu \\ Intensive Care Unit \\ the First Hospital \\ of Jilin University \\ 71 Xinmin Avenue \\ 130021 Changchun, China \\ Phone: +86 0431-88782222 \\ E-mail: yinglu2891@aliyun. \\ com
}


Cordyceps polysaccharide is the main active ingredient of Chinese caterpillar fungus, which not only plays a significant anti-tumor $[6,7]$, immunopotentiation [8], and anti-radiation [9] role but also has multiple protective effects on the liver [10, $11]$, such as decreasing circulating TNF- $\alpha$ level and attenuating oxidative injury, possibly by reducing NOX activity and inhibiting ROS production in an LPS-induced acute liver model, and especially can be used as a good suppressive factor for transplant rejection $[12,13]$. This study is based on the Chinese medical treatment strategy of liver diseases in which cordyceps polysaccharide was used as a treatment of ALF, whereas there is no domestic or international research on the action, and its mechanism, of cordyceps polysaccharide on ALF.

\section{Material and methods}

\section{Animals}

Sixty healthy 3-month-old male SPF SD rats, weighing 80-120 g, were purchased from the Experimental Animal Center of Sun Yat-sen University and housed at $20-28^{\circ} \mathrm{C}$ under constant humidity conditions with access to food and water ad libitum. The experiments were conducted 1 week later. All animal procedures were approved by the Institutional Animal Care and Use Committee of JiLin University, and the number of the Ethics Committee agreement is 2013-252.

\section{Acute liver injury mouse model}

Twelve rats were randomly chosen for group A (control), and the remaining rats were used to establish the ALF model and randomly divided into four groups (group B, C, D and E). The four experimental groups were injected intraperitoneally with $700 \mathrm{mg} / \mathrm{kg}$ D-galactosamine and $20 \mu \mathrm{g} / \mathrm{kg}$ lipopolysaccharide LPS [14], while the control group received normal saline only. Twenty-four hours later, groups C, D, E received cordyceps polysaccharide (Shanghai Biological Engineering Company, Shanghai, China) at the dose of $20 \mathrm{mg} / \mathrm{ml}$, $10 \mathrm{mg} / \mathrm{ml}$ and $5 \mathrm{mg} / \mathrm{ml}$ respectively, and group $B$ received isochoric normal saline. All the cordyceps polysaccharide was given with the method of gavage, once a day. All the rats in all five groups were divided into three groups randomly, and were sacrificed to obtain serum samples and livers at the first day, third day and seventh day. All rats had stomachs stuffed once a day. All of the experiments were approved by the Sun Yat-sen University Animal Ethics Committee.

\section{Sample acquisition and processing}

Blood samples and liver tissue samples were collected from all groups for assessing the liver function and cytokines, and stored at $-80^{\circ} \mathrm{C}$. The rats were euthanized, the abdominal cavity was cut layer-by-layer, the liver specimens were fixed with $4 \%$ poly-carboxylic acid, and histopathologic evaluation and protein detection were performed.

\section{Histopathologic examination}

Liver tissue specimens were harvested and fixed in 4\% neutral a leaven 2-3 days. Stone vinegar was used for conventional embedment, section, and staining. The liver sections were visualized under light microscopy for morphologic analysis of pathologic changes.

\section{Apoptosis detection}

Liver specimens were collected from each group at the first day, third day and seventh day respectively, then fixed in paraformaldehyde and embedded in paraffin. Paraffin slices $(4-6 \mu \mathrm{m})$ were dewaxed and flooded, and soaked in $3 \% \mathrm{H}_{2} \mathrm{O}_{2}$ for $10 \mathrm{~min}$ at room temperature. The paraffin slices were washed with distilled water, digested with $200 \mathrm{U}$ of freshly diluted trypsin $\mathrm{K}$ for $10 \mathrm{~min}$ at $37^{\circ} \mathrm{C}$, and rinsed with $0.01 \mathrm{M}$ Tris-buffered saline (TBS). Twenty microliters of a labeling buffer solution mixture (designated as the marking solution) was dripped onto each slice $(1 \mu \mathrm{l}$ of TdT, $1 \mu \mathrm{l}$ of DIG-d-UTP, and $18 \mu$ l of labeling buffer solution). The slices were placed in a humidified chamber and incubated for $2 \mathrm{~h}$ at $37^{\circ} \mathrm{C}$.

The slices were rinsed extensively with $0.01 \mathrm{M}$ TBS, $50 \mu \mathrm{l}$ of blocking solution was dropped onto each slice, incubated for $30 \mathrm{~min}$ at room temperature, then the blocking solution was removed. Dilute biotinylated digoxin $(50 \mu \mathrm{l} ; 1$ : 100 antibody dilution) was dropped onto the slices.

The slices were placed in a humidified chamber for $30 \mathrm{~min}$ at $37^{\circ} \mathrm{C}$, rinsed with 0.01 MTBS, streptococcus avidin-biotin complex (SABC) antibody diluted $1: 100$, and mixed. Fifty microliters of dilute $\mathrm{SABC}$ was dropped onto each slice, reacted for $30 \mathrm{~min}$ at $37^{\circ} \mathrm{C}$, then washed three times with 0.01 M TBS for 5 min each wash. The DAB color reaction was as follows: one drop of reagents $A$, $B$, and $C$ from the DAB boxes into $1 \mathrm{ml}$ of distilled water; mixed; dropped on the specimens; washed after the color reaction; and stained with hematoxylin. The specimens were transparently processed, mounted with neutral gum, and observed under an optical microscope; the apoptotic nuclei stained brown.

\section{Western blot analysis}

Liver tissue samples of each group were collected on day 7 and washed twice with PBS. Four hundred microliters of cell lysate were added to each bottle, then $40 \mu \mathrm{l}$ of PMSF was added. The 
bottles were gently shaken to mix, and placed on ice for $10 \mathrm{~min}$ to allow uniform tissue lysis. Then, the liver specimens were repeatedly aspirated and dispensed with a sterile syringe, the lysate was placed in an EP tube on ice bathed for $30 \mathrm{~min}$, and centrifuged at $12,000 \mathrm{~g}$ for $15 \mathrm{~min}$. The serum supernatant was transferred into a new EP tube, $20 \mu$ l of protein sample buffer was added to every $100 \mu \mathrm{l}$ of serum, boiled for 5 min, mixed evenly, and preserved at $-80^{\circ} \mathrm{C}$. The sample underwent separation on $12 \%$ sodium dodecyl sulfate-polyacrylamide gel electrophoresis (SDS-PAGE) protein electrophoresis, the separated protein belts were transferred to PVDF membranes using the wet method, sealed under room temperature for $1 \mathrm{~h}$, then the first antibodies (caspase-1, IL-18, IL-10, VEGF, and SDF-1 $\alpha$ (all at a $1: 1000$ dilution)) purchased from BD Biosciences were added for overnight incubation at $4^{\circ} \mathrm{C}$. After washing with Tris-buffered saline (TBS) or TBS-Tween, the membranes were incubated with the appropriate secondary antibody for $1 \mathrm{~h}$ at room temperature. Then, the second antibody was eluted, chemiluminescence was applied for color development and fixation, and the expression of caspase-1, IL-18, IL-10, vascular endothelial growth factor (VEGF), and stromal cell derived factor- $1 \alpha$ (SDF- $1 \alpha)$ proteins was determined.

\section{Enzyme-linked immunosorbent assay (ELISA)}

Serum samples from each rat group were collected at the first day, third day and seventh day and detected for alanine aminotransferase (ALT), aspartate transaminase (AST), alkaline phosphatase (ALP) and DBIL with a commercial ELISA lit (Shanghai Biological Engineering Company). A standard sample dilution $(0.5 \mathrm{ml})$ was added to lyophilized standard samples, dissolved for $15 \mathrm{~min}$, mixed gently, and diluted as follows in $\mathrm{pg} / \mathrm{ml}$ : 2000, 1000, 500, 250, 125, 62.5, 31.25, and 0 . To the $80 \mu \mathrm{l}$ standard sample dilution, $100 \mu \mathrm{l}$ of sample was added and mixed with $10 \mu$ of $1 \mathrm{~N}$ $\mathrm{HCL}$. The specimen was placed for $60 \mathrm{~min}$ at $4^{\circ} \mathrm{C}$, $10 \mu$ l of $1 \mathrm{~N} \mathrm{NaOH}$ was added, and mixed. The slats were removed, a standard sample and sample dilution was added to blank holes, and the remaining corresponding holes were filled with standard samples of different densities. The holes were sealed with adhesive tape and placed at $37^{\circ} \mathrm{C}$ for $90 \mathrm{~min}$. The concentrated biotinylated antibody was diluted into a $1: 30$ working solution, placed in the dark at room temperature, and the microplate was washed 5 times. An enzyme-conjugated dilution was added to the blank holes, and an enzyme-conjugated working solution was added to the remaining holes. The holes were sealed with new adhesive tape for the reaction, placed at $37^{\circ} \mathrm{C}$ for $30 \mathrm{~min}$, and the microplate was washed 5 times. One hundred microliters of chromogenic substrate (TMB) was added per hole and placed in the dark at $37^{\circ} \mathrm{C}$ for $15 \mathrm{~min}$. After adding the stop solution and mixing evenly, the OD450 value was immediately measured with a microplate reader (ELX800; BIO-TEK Company, England). The experiment was performed 3 times.

\section{Synovial fluid PCNA and SIRP- $\alpha 1$ content detection using the PCR method}

The liver tissues were removed and prepared as follows: $1 \mathrm{ml}$ of Trizol reagent (BD Biosciences) was added to full cleavage; $0.2 \mathrm{ml}$ of chloroform was added; the suspension was shaken; ice bathed for $5 \mathrm{~min}$; centrifuged at 12,000 rpm for $20 \mathrm{~min}$ at $4^{\circ} \mathrm{C}$; an equal volume of isopropanol was added to the suspension on ice for $5 \mathrm{~min}$; centrifuged at $12,000 \mathrm{rpm}$ for $20 \mathrm{~min}$ at $4^{\circ} \mathrm{C}$; the supernatant was discarded; $1 \mathrm{ml}$ of $75 \%$ ethanol was added; centrifuged at 10,000 rpm for $5 \mathrm{~min}$ at $4^{\circ} \mathrm{C}$; the supernatant was removed; the EP tube was inverted; dried at room temperature for $15 \mathrm{~min} ; 20 \mu \mathrm{l}$ of RNase-free dd $\mathrm{H}_{2} \mathrm{O}$ was added to dissolve the sediment; $1 \mu$ l of lysate was $a b$ sorbed and the remaining portion was placed in $\mathrm{a}-70^{\circ} \mathrm{C}$ refrigerator; the $1 \mathrm{ml}$ lysate was diluted to $80 \mu \mathrm{l}$; the OD260 and OD280 were measured on a spectrophotometer; and the total RNA was calculated. Reverse-transcription reactions were performed using the SuperScript First-Strand Synthesis System (Sigma, St. Louis, MO, USA) as described previously [15]. Sample mRNA levels were semiquantified by RT-PCR or quantified by real-time RT-PCR as previously described [16]. The proliferating cell nuclear antigen (PCNA), signal regulatory protein- $\alpha 1$ (SIRP- $\alpha 1$ ), and GAPDH gene sequences of the primers were as follows: PCNA, TCCCAGTTCACCATCCATGTC and GGTCCCCTAAGGCCCATTCCT; sIRP- $\alpha 1$, ACAGATGAAGTGCTGCTTCC and GTCGGAGTTTCCTAGCTGGAT; and GAPDH, TCCTCCCATCAGCATCGCCC' and ACACGCGGATGACGGGCA.

\section{Statistical analysis}

All results reported are representative of at least three separate experiments, and are expressed as mean \pm SD. Between-group differences were analyzed using analysis of variance (ANOVA) and $t$-tests, with significance defined as $p<0.05$.

\section{Results}

\section{TUNEL staining of hepatic cells}

Liver tissue apoptotic cells appeared after the first day. There were few liver tissue apoptotic cells in the normal group, but an abundance of 
liver tissue apoptotic cells in the model group; the difference was statistically significant. After the administration of medication, the number of apoptotic cells decreased in a dose-dependent manner (Figure 1).

\section{Levels of ALT, AST, ALP, and TBIL}

There were no significant differences of ALT, AST, ALP, and total bilirubin (TBIL) in the plasma of normal rats at the 3 time points $(1,3$, and 7 days). The groups treated with cordyceps polysaccharide showed lower levels of ALT, AST, ALP, and TBIL in the plasma than the groups of ALF which only received the physiological saline (Figure 2). These results indicated that cordyceps polysaccharide can decrease the liver injury significantly, especially in a high dose.

\section{Pathologic results}

The control group showed diffuse necrosis of liver cells, hepatic cord dissociation, vague lobular structure, an abundance of bridging necrosis, a large number of lymphocytes infiltrated in the
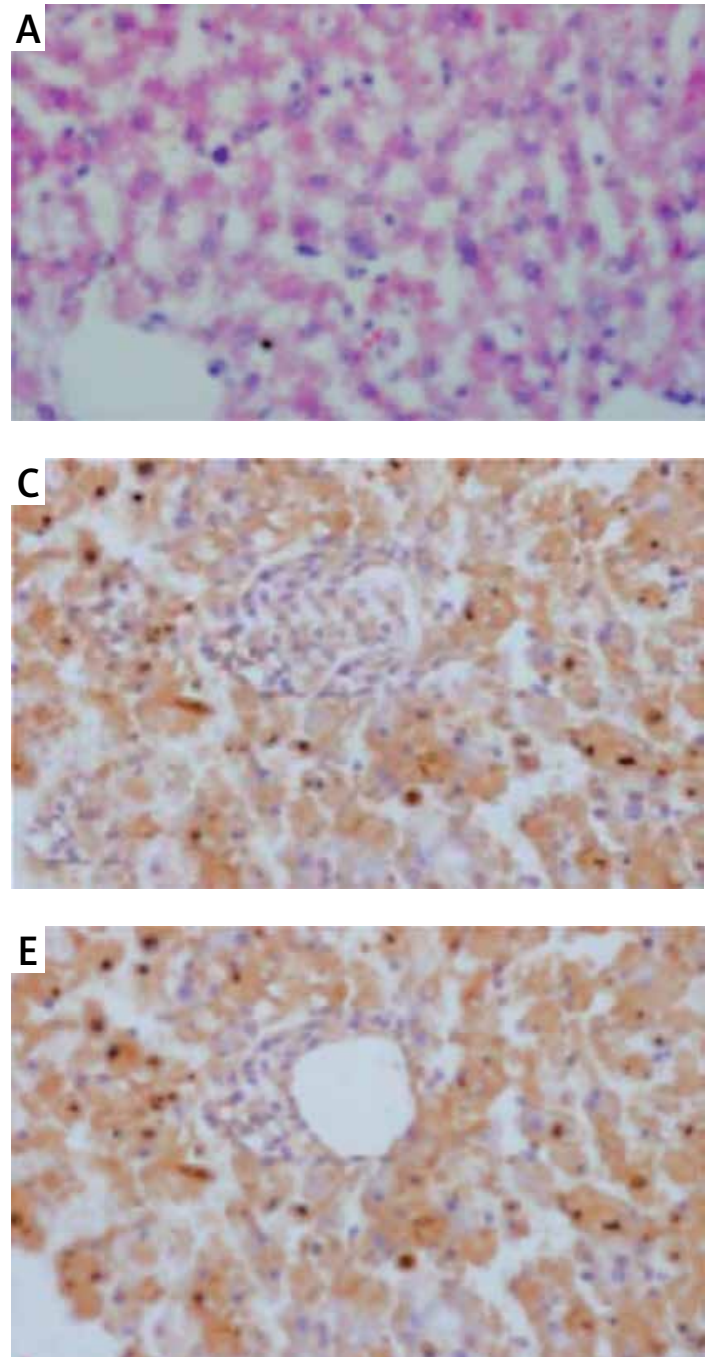

lobular and periportal areas, and edema and degeneration of residual liver cells at day seven. These findings suggest successful modeling of ALF, and the groups exposed to cordyceps polysaccharide showed a significant reduction of inflammatory cell infiltration, gradual lobular structure recovery, visible bile duct hyperplasia around the periportal area, and normal liver cells, especially in the high-dose group (Figure 3). Thus, the cordyceps polysaccharide with a high dose could improve the pathological features of ALF.

\section{Expression level of caspase-1, IL-18, IL-10,} VEGF, and SDF-1 $\alpha$ protein in liver tissue

Based on Western blot analysis, the GAPDH protein belts were uniform in brightness, suggesting that the amounts of protein were basically the same in these samples. The groups exposed to medication showed lower expression levels of caspase-1, IL-18, and IL-10, but higher expression levels of VEGF, IL-10, and SDF-1 $\alpha$ compared with the comparison group, especially in the group with high-dose medication (Figure 4). These results in-
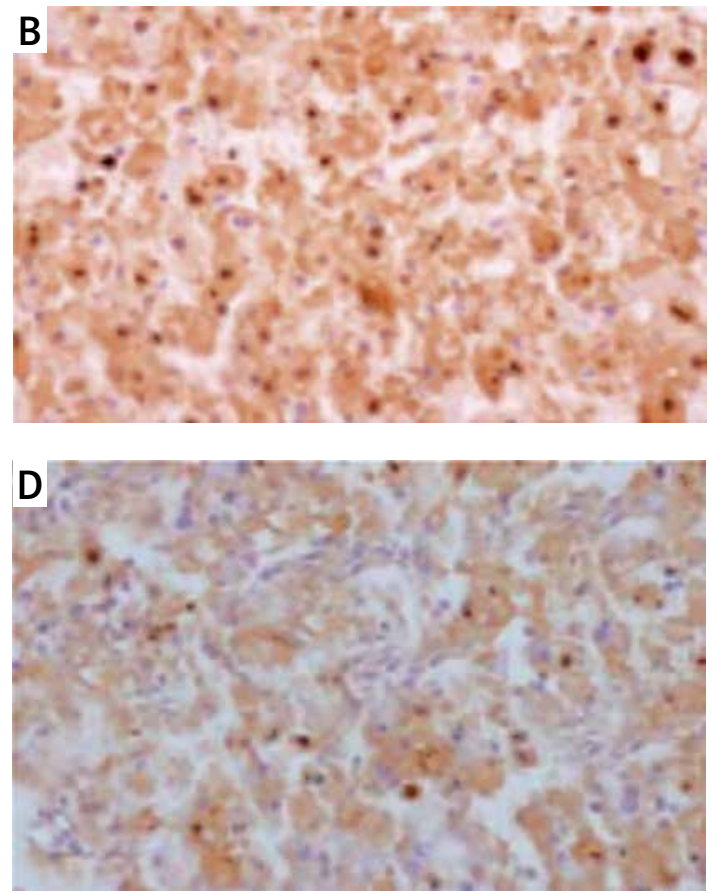

Figure 1. TUNEL staining of hepatic cells (400x). A - normal group, $\mathbf{B}$ - model group, $\mathbf{C}$ - cordyceps polysaccharide high-dose group, D - cordyceps polysaccharide intermediate-dose group, E - cordyceps polysaccharide low-dose group 

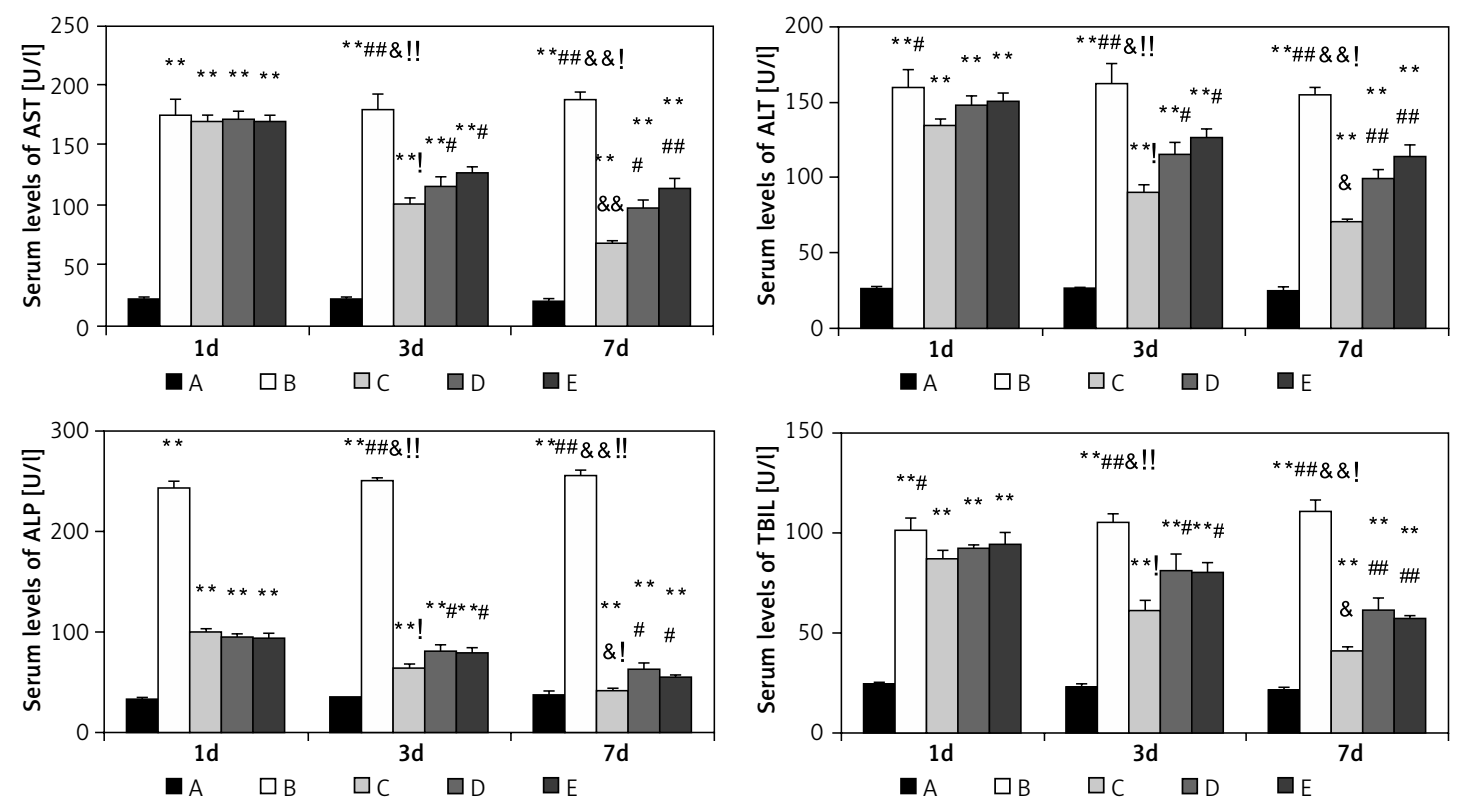

Figure 2. Alanine aminotransferase (ALT), aspartate transaminase (AST), alkaline phosphatase (ALP), and total bilirubin (TBIL) content measured using the ELISA method. A - normal group, B - model group, C - cordyceps polysaccharide high-dose group, D - cordyceps polysaccharide intermediate-dose group, E - cordyceps polysaccharide low-dose group
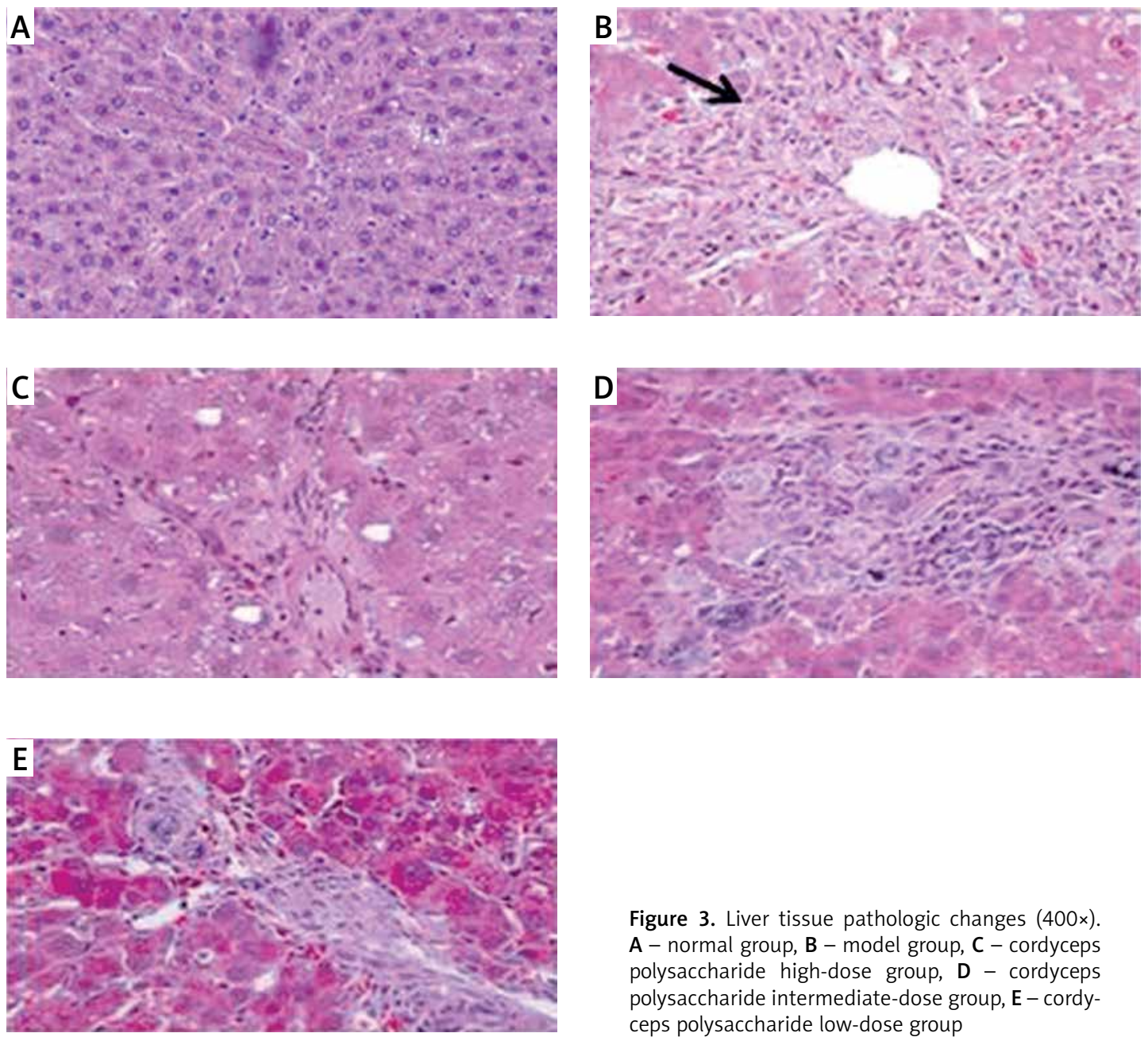

Figure 3. Liver tissue pathologic changes (400x). A - normal group, B - model group, C - cordyceps polysaccharide high-dose group, D - cordyceps polysaccharide intermediate-dose group, E - cordyceps polysaccharide low-dose group 

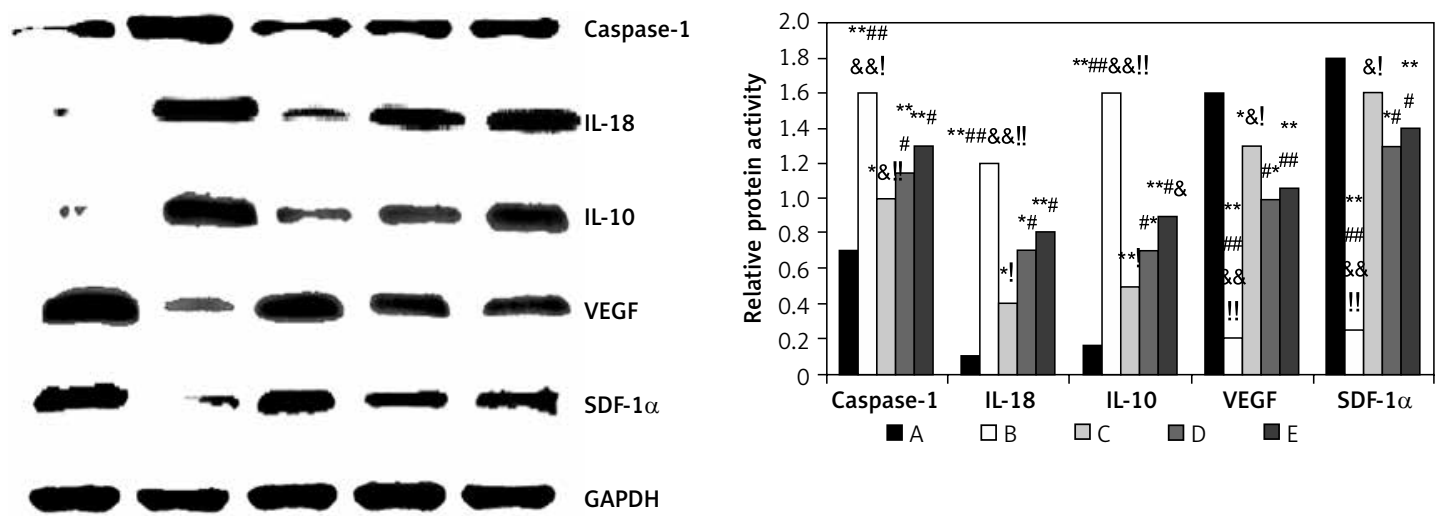

Figure 4. Medication effects on the expression of proteins. A - normal group, B - model group, $\mathrm{C}$ - cordyceps polysaccharide high-dose group, D - cordyceps polysaccharide intermediate-dose group, E - cordyceps polysaccharide low-dose group

${ }^{* *} p<0.01$ vs. group $A,{ }^{\# \#} p<0.01$ vs. group $C ;{ }^{\#} p<0.05$ vs. group $C ;{ }^{\&} \&<0.01$ vs. group $D,{ }^{\&} p<0.05$ vs. group $D, "$, $p<0.01$ vs. group $E, ' p<0.05$ vs. group $E$.

dicated that high-dose cordyceps polysaccharide could suppress the inflammation response in ALF.

\section{Expression of PCNA and SIRP- $\alpha 1$ in rat liver tissues}

In the normal group, the expression levels of PCNA and SIRP- $\alpha 1$ were very low, which was significantly different from the model and $\mathrm{pHGF}$ groups. However, the expression level of SIRP- $\alpha 1$ in the groups exposed to medication increased in a dose-dependent manner (Figure 5). These data suggested that high-dose of cordyceps polysaccharide could facilitate cell proliferation and liver regeneration.

\section{Discussion}

We established the rat ALF models by combining D-galactosamine with LPS, which has similar morphological features as human ALF, and analyzed the effects of cordyceps polysaccharide on rat liver function.

Serum ALT and AST levels were elevated, and the levels of caspase-1 and IL-18 in ALF rat liver tissues were significantly increased and higher in the model group compared with the control group. Liver function was more deteriorated and severe in group B than other groups [17], which indicated that caspase-1 and IL-18 may play a very important role in the pathogenesis of ALF, and also suggested that caspase-1 and IL-18 can serve as diagnostic and prognostic marker proteins for ALF [18-20]. After medication, the expression levels of caspase-1 and IL-18 in liver tissue improved gradually with the alleviation of liver inflammation. These results were clearly different in the highdose medication group, suggesting that the medication effect is synergistic. The significant difference between medication and control groups at the third day and seventh day indicated that medication can decrease the level of caspase- 1 and IL-18 by decreasing the systemic inflammatory response and inhibiting immune cell proliferation. Medication could regulate the equilibrium of pro- and anti-inflammatory factors, which may be an effective treatment for ALF. The variation in caspase- 1 and IL-18 in the process of treatment also reflects the efficacy and prognosis of ALF.

Although the liver has a strong ability to regenerate, the lack of effective liver regeneration is still a major causal factor for lethality [21]. It has been reported that there is hope for survival when the hepatocyte remnants are more than $45 \%$, and death due to liver failure is a certainty when less than $12 \%$ [22-24]. Therefore, it is of great importance to study the regeneration of liver cells in ALF. PCNA is a type of nuclear acidic protein that is closely related to cell proliferation, which could reflect the cell proliferation effectively [25-29].

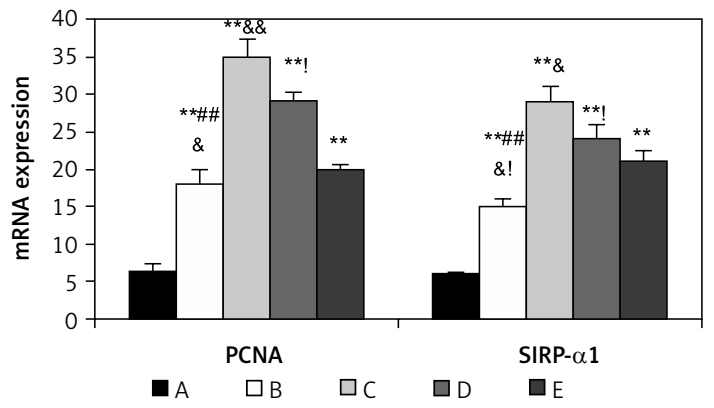

Figure 5. Expression of proliferating cell nuclear antigen (PCNA) and signal regulatory protein- $\alpha 1$ (SIRP- $\alpha 1)$ after medication. A - normal group, B - model group, C - cordyceps polysaccharide high-dose group, D - cordyceps polysaccharide intermediate-dose group, E - cordyceps polysaccharide low-dose group

${ }^{* *} p<0.01$ vs. group $A,{ }^{\# \#} p<0.01$ vs. group $C,{ }^{*} p<0.05$ vs. group $C$, ${ }^{\& \&} p<0.01$ vs. group $D,{ }^{\&} p<0.05$ vs. group $D$, "l $p<0.01$ vs. group $E, ' p<0.05$ vs. group $E$. 
SIRP- $\alpha 1$, a negative regulatory factor, is involved in the entire process of liver regeneration [30], and participates in the regulatory process directly or indirectly with other positive or negative factors, especially in the termination of liver regeneration and proliferation, which may have important biological implications. Thus, cordyceps polysaccharide can effectively enhance the expression of PCNA and SIRP- $\alpha 1$, and accelerate the regeneration of liver cells. However, there were still several limitations in our study. The three groups treated with cordyceps polysaccharide showed no significant difference in the levels of ALT, AST, ALP, and TBIL, and we did not perform in vitro experiments on the role of cordyceps polysaccharide.

In conclusion, cordyceps polysaccharide can also specifically home to the damaged liver, and promote the secretion of VEGF, hepatocyte proliferation, liver vascular regeneration, and liver tissue repair. Medication can reduce the level of IL-10, and regulate the balance of pro- and anti-inflammatory cytokines. Caspase-1 and IL-18 play an important role in the pathogenesis of liver failure and liver cell apoptosis. Medication also can reduce the levels of caspase- 1 and IL-18, which are thought to be the predictors for ALF and future therapeutic targets. In summary, cordyceps polysaccharide can reduce the immune response and inflammatory injury in ALF and suppress liver cell apoptosis.

\section{Conflict of interest}

The authors declare no conflict of interest.

\section{References}

1. Sun HJ, Chen J, Zhang H, et al. Von Willebrand factor protects against acute $\mathrm{CCl} 4$-induced hepatotoxicity through phospho-p38 MAPK signaling pathway inhibition. Immunol Res 2017; 65: 1046-58.

2. Piechota M, Piechota A, Misztal M, Bernas S, PietraszekGrzywaczewska I. An evaluation of the usefulness of extracorporeal liver support techniques in patients with severe liver dysfunction. Arch Med Sci 2017; 15: 99-112.

3. Salama H, Zekri AR, Zern M, et al. Autologous hematopoietic stem cell transplantation in 48 patients with end-stage chronic liver diseases. Cell Transplant 2010; 19: 1475-86.

4. Ismail A, Fouad O, Abdelnasser A, Chowdhury A, Selim A. Stem cell therapy improves the outcome of liver resection in cirrhotics. J Gastrointest Cancer 2010; 41: 17-23.

5. Bajek A, Olkowska J, Drewa T. Mesenchymal stem cells as a therapeutic tool in tissue and organ regeneration. Postepy Hig Med Dosw 2011; 65: 124-32.

6. Lin S, Lyu X, Yu J, et al. MHP-1 inhibits cancer metastasis and restores topotecan sensitivity via regulating epithelial-mesenchymal transition and TGF-beta signaling in human breast cancer cells. Phytomedicine 2016; 23: 1053-63.
7. Yang S, Zhang H. Optimization of the fermentation process of Cordyceps sobolifera Se-CEPS and its anti-tumor activity in vivo. J Biol Eng 2016; 10: 8.

8. Yang WS, Nam GS, Kim MY, Cho JY. Syk-mediated suppression of inflammatory responses by Cordyceps bassiana. Am J Chin Med 2017; 45: 1217-32.

9. Wong WC, Wu JY, Benzie IF. Photoprotective potential of Cordyceps polysaccharides against ultraviolet B radiation-induced DNA damage to human skin cells. Br J Dermatol 2011; 164: 980-6.

10. Hung YP, Lee CL. Higher anti-liver fibrosis effect of cordyceps militaris-fermented product cultured with deep ocean water via inhibiting proinflammatory factors and fibrosis-related factors expressions. Mar Drugs 2017; 15: 168.

11. Li J, Zhong LP, Zhu HB, Wang FZ. The protective effect of cordycepin on D-galactosamine/lipopolysaccharide-induced acute liver injury. Mediators Inflamm 2017; 3946706.

12. Ong BY, Aziz Z. Efficacy of cordyceps sinensis as an adjunctive treatment in kidney transplant patients: a systematic-review and meta-analysis. Complement Ther Med 2017; 30: 84-92.

13. Li Y, Xue WJ, Tian PX, et al. Clinical application of cordyceps sinensis on immunosuppressive therapy in renal transplantation. Transplant Proc 2009; 41: 1565-9.

14. Wang Y, Gao LN, Cui YL, Jiang HL. Protective effect of danhong injection on acute hepatic failure induced by lipopolysaccharide and d-galactosamine in mice. Evid Based Complement Alternat Med 2014: 153902.

15. Jin J, Lv X, Chen L, et al. Bmi-1 plays a critical role in protection from renal tubulointerstitial injury by maintaining redox balance. Aging Cell 2014; 13: 797-809.

16. Yin Y, Wang Q, Sun W, et al. p27(kip1) deficiency accelerates dentin and alveolar bone formation. Clin Exp Pharmacol Physiol 2014; 41: 807-16.

17. Yumoto E, Higashi T, Nouso K, et al. Serum gamma-interferon-inducing factor (IL-18) and IL-10 levels in patients with acute hepatitis and fulminant hepatic failure. J Gastroenterol Hepatol 2002; 17: 285-94.

18. Tang J, Wang J, Guo L, et al. Mesenchymal stem cells modified with stromal cell-derived factor 1 alpha improve cardiac remodeling via paracrine activation of hepatocyte growth factor in a rat model of myocardial infarction. Mol Cells 2010; 29: 9-19.

19. Friedman SL. Hepatic stellate cells: protean, multifunctional, and enigmatic cells of the liver. Physiol Rev 2008; 88: 125-72.

20. Luo P, Tan Z, Zhang Z, Li H, Mo Z. Inhibitory effects of salvianolic acid $B$ on the high glucose-induced mesangial proliferation via NF-kappaB-dependent pathway. Biol Pharm Bull 2008; 31: 1381-6.

21. Theocharides AP, Jin L, Cheng PY, et al. Disruption of SIRPalpha signaling in macrophages eliminates human acute myeloid leukemia stem cells in xenografts. J Exp Med 2012; 209: 1883-99.

22. Yu LX, Yan HX, Liu Q, et al. Endotoxin accumulation prevents carcinogen-induced apoptosis and promotes liver tumorigenesis in rodents. Hepatology 2010; 52: 1322-33.

23. Gordon S, Taylor PR. Monocyte and macrophage heterogeneity. Nat Rev Immunol 2005; 5: 953-64.

24. Kim S, Takahashi H, Lin WW, et al. Carcinoma-produced factors activate myeloid cells through TLR2 to stimulate metastasis. Nature 2009; 457: 102-6.

25. Fisher PA, Moutsiakis DL, McConnell M, Miller $H$, Mozzherin DJ A single amino acid change (E85K) in human PCNA that leads, relative to wild type, to enhanced 
DNA synthesis by DNA polymerase delta past nucleotide base lesions (TLS) as well as on unmodified templates. Biochemistry 2004; 43: 15915-21.

26. Zhang H, Xiong $\mathrm{Y}$, Beach D. Proliferating cell nuclear antigen and p21 are components of multiple cell cycle kinase complexes. Mol Biol Cell 1993; 4: 897-906.

27. Koundrioukoff S, Jonsson ZO, Hasan S, et al. A direct interaction between proliferating cell nuclear antigen (PCNA) and Cdk2 targets PCNA-interacting proteins for phosphorylation. J Biol Chem 2000; 275: 22882-7.

28. Song HS, Lim HJ, Das SK, Paria BC, Dey SK. Dysregulation of EGF family of growth factors and COX-2 in the uterus during the preattachment and attachment reactions of the blastocyst with the luminal epithelium correlates with implantation failure in LIF-deficient mice. Mol Endocrinol 2000; 14: 1147-61.

29. Kutwin M, Sawosz E, Jaworski S, et al. Investigation of platinum nanoparticle properties against U87 glioblastoma multiforme. Arch Med Sci 2017; 13: 1322-34.

30. Nilsson EE, Kezele P, Skinner MK. Leukemia inhibitory factor (LIF) promotes the primordial to primary follicle transition in rat ovaries. Mol Cell Endocrinol 2002; 188: 65-73. 